\title{
Mathematical modeling of low-frequency diagnostic vibration- acoustic vibrations of linear-extended energy objects of housing and communal services
}

\author{
Zakharova V.E. ', Gaponenko S.O. ' , Fedotova A.O. ${ }^{1}$ \\ ${ }^{1}$ Kazan state power engineering university, 420066, Russia, Kazan
}

\begin{abstract}
A modal analysis of natural vibrations of polyethylene pipelines is proposed, which is a calculation of the vertical and lateral pressure exerted by the soil on the pipelines, on the basis of which the study of vibrations in the ANSYS software package was carried out. The results of modal analysis are presented for polyethylene pipes with a layout with inclined walls and various soils.
\end{abstract}

\section{Introduction}

Pipeline systems are the basis of the system for providing the population, production and agriculture with vital products: clean air, drinking and process water, high and low-grade heat carrier (heat), gas, oil products. They also dispose of numerous waste (domestic and industrial wastewater, polluted air, flue gases, garbage and solid waste) [1-2].

For the reliable and sustainable development of society, 2 million $\mathrm{km}$ of underground pipelines have been laid in pipeline systems of water supply, sewerage, heat and gas supply, oil and gas pipelines in Russia. In the internal communal systems of buildings, the length of pipelines is 3-5 million $\mathrm{km}$.

Of this huge number of pipes, about half is in the housing and communal services (HCS), providing the population of Russia with all the necessary utilities [3].

\section{Types of pipelines for housing and communal services}

Depending on the application and purpose, pipes are made of metal and plastic.

Nowadays, plastic pipes are increasingly used. The new material is used in the housing and utilities sector for the arrangement of water supply and sewerage systems. Outdated designs are being replaced with lightweight, practical and durable plastic.

At the moment, in Russia the most widely used pipes are made of cross-linked polyethylene, polypropylene, as well as metal-polymer pipes based on them [4].

\section{Goals and objectives of the work}

There are many methods of technical diagnostics of pipelines, one of which is the method of oscillations.
Vibrational vibrations are excited in the control object and their parameters are analyzed at some distance from the excitation point. The most informative are natural oscillations, the frequency of which depends on the parameters of the controlled object.

The task becomes more complicated when the controlled object is under an external influence capable of influencing the natural frequency. In particular, for pipelines, such an effect may be the effect of the soil during channelless laying. In this case, there is a change in the parameters of natural vibrations, which coarsens and often simply distorts the results of vibration control.

Different types of soil have different effects on the change in the natural frequency of the pipeline. The aim of the work is to analyze the influence of various soils on the parameters of natural vibrations of the pipeline.

Previously, our team experimentally determined that the impact of various soils changes the natural frequency of the pipeline downward. The objective of this study is to theoretically confirm the dependence of the change in the vibration frequency of the pipeline when exposed to soil.

\section{Calculation parameters}

For the calculation, 5 polyethylene pipes were selected with the following characteristics: $125 \times 3.1 ; 180 \times 4.4$; $250 \times 6.2 ; 355 \times 8.7$ and $630 \times 15.4$. The parameters correspond to the requirements of GOST 18599-2001 "Polyethylene pressure pipes" [5].

According to the modeling conditions, the pipeline is fixed on both sides at a distance of $0.22 \mathrm{~L}$, where $\mathrm{L}$ is 


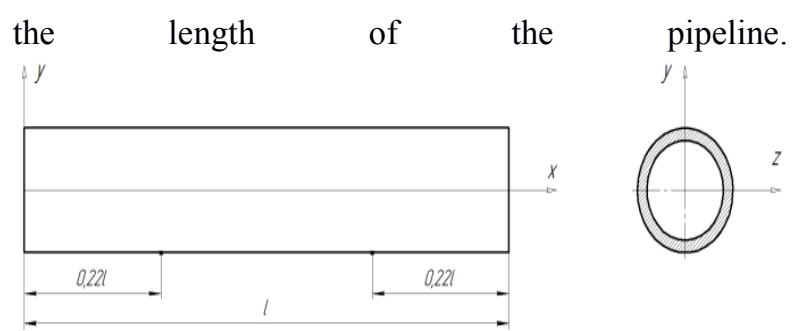

Fig. 1. Design diagram of a pipeline fixed on both sides at a distance of $0.22 \mathrm{~L}$.

Figure 1 shows the design diagram of a pipeline with a diameter of $180 \mathrm{~mm}$, a pipe wall thickness of 4.4 $\mathrm{mm}$. The design pipeline is laid in a trench with inclined walls, the slope is laid on a flat base at a depth of $2.5 \mathrm{~m}$ in sandy soil (G-I). The specific gravity of the soil is $16.7 \mathrm{kN} / \mathrm{m}^{3}$ and the modulus of deformation of the soil is $1.1 \mathrm{MPa}$.

\section{Principles of mathematical modeling of the impact of external load on pipelines}

To construct a mathematical model, the degree of soil impact on the pipeline was determined due to vertical and lateral soil pressure on the polyethylene pipeline [6-7].

The concentration factor of the pressure of the backfill soil when laying pipes on undisturbed soil in the embankment is determined by the formula (1):

$$
K_{H}=\frac{3\left(P_{p}+P_{S}\right)}{2\left(P_{p}+2 P_{S}\right)}
$$

where $P_{P}$ - pipeline stiffness according to M. Levy, $\mathrm{MPa}$;

$P_{S}$ - backfill soil stiffness, MPa.

Vertical and lateral soil pressure on the polyethylene pipeline, $\mathrm{kN} / \mathrm{m}(2-3)$ :

$$
\begin{gathered}
Q_{S}^{V}=n \gamma H D_{H} K_{H} \\
Q_{S}^{L}=n \gamma\left(H+\frac{D_{H}}{2}\right) D_{H} \lambda_{H}
\end{gathered}
$$

where $n$ - overload factor for external, permanent and temporary loads;

$\gamma$ - specific gravity of soil, $\mathrm{kN} / \mathrm{m}^{3}$;

$D_{H}$ - pipe outer diameter, m;

$K_{H}$ - the concentration factor of the pressure of the backfill soil when laying pipes on undisturbed soil in the embankment;

$H$ - pipeline immersion depth, $\mathrm{m}$;

$\lambda_{H}-$ coefficient at the normal degree of compaction of the backfill.

Based on the data obtained, the pressure, $\mathrm{kN} / \mathrm{m}^{2}$, exerted by the soil on the pipeline is determined (4):

$$
q=\frac{Q_{E}}{D_{H}}
$$

where $Q_{E}$ - calculated linear reduced equivalent load, $\mathrm{kN} / \mathrm{m}$.

\section{Calculation}

The calculations were performed in the ANSYS, a universal software system for finite element analysis, which is quite popular among specialists in the field of automated engineering calculations [8-12].

The parameters of polyethylene pipelines and two types of soils were taken as the initial data, in particular, the two most common soil categories in Russia, presented in Table 1, were selected.

Table 1. Categories of the soil in question

\begin{tabular}{|c|l|c|c|}
\hline \multirow{2}{*}{$\begin{array}{c}\text { Soil } \\
\text { category }\end{array}$} & \multicolumn{2}{|c|}{ Name of soil } & \multicolumn{2}{|c|}{$q, \mathrm{kN} / \mathrm{m}^{3}$} \\
\cline { 3 - 4 } & & $355 \times 8,7$ & $630 \times 15,4$ \\
\hline G -I & $\begin{array}{l}\text { Gravelly, coarse } \\
\text { and medium-sized } \\
\text { sands }\end{array}$ & 48,9908462 & 48,7741223 \\
\hline G -VI & Heavy clays & 58,9495442 & 58,8673744 \\
\hline
\end{tabular}

The results of calculating the frequencies of natural vibrations of various pipelines, without taking into account the influence of the soil and taking it into account, are presented in Tables 2 and 3. It shows the natural frequencies $v[\mathrm{~Hz}]$ (modes from 1 to 100 ) of various standard sizes of pipelines without the

\begin{tabular}{|c|c|c|c|c|c|c|c|c|c|}
\hline \multirow[b]{3}{*}{ Mode } & \multicolumn{9}{|c|}{ Meter pipeline } \\
\hline & \multicolumn{3}{|c|}{$125 \times 3,1$} & \multicolumn{3}{|c|}{$180 \times 4,4$} & \multicolumn{3}{|c|}{$250 \times 6,2$} \\
\hline & - & $\begin{array}{l}\text { G } \\
-\mathrm{I}\end{array}$ & $\begin{array}{l}\text { G - } \\
\text { VI }\end{array}$ & - & $\begin{array}{l}\text { G } \\
-I\end{array}$ & $\begin{array}{c}\text { G } \\
- \\
\text { VI }\end{array}$ & - & $\begin{array}{c}\text { G - } \\
\text { I }\end{array}$ & $\begin{array}{c}\text { G } \\
- \\
\text { VI }\end{array}$ \\
\hline 1 & 2 & 3 & 4 & 5 & 6 & 7 & 8 & 9 & 10 \\
\hline & \multicolumn{8}{|c|}{ Frequency, $\mathrm{Hz}$} & \\
\hline 1 & $\begin{array}{l}\infty \\
\stackrel{\infty}{+} \\
\stackrel{+}{+}\end{array}$ & 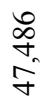 & $\begin{array}{l}\overrightarrow{\widetilde{d}} \\
\text { fo }\end{array}$ & $\stackrel{n}{\hat{n}}$ & $\begin{array}{l}\infty \\
\stackrel{\infty}{\infty} \\
\underset{+}{\infty}\end{array}$ & $\begin{array}{l}\vec{b} \\
+ \\
+\infty\end{array}$ & $\begin{array}{l}\text { n̂. } \\
\hat{n} \\
\tilde{c}\end{array}$ & $\begin{array}{l}\hat{b} \\
+ \\
\tilde{\imath}\end{array}$ & 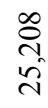 \\
\hline 2 & $\stackrel{\infty}{\stackrel{\infty}{=}}$ & $\begin{array}{l}\text { N } \\
\text { ป } \\
\text { In }\end{array}$ & $\begin{array}{l}\text { J0 } \\
0 \\
\Xi\end{array}$ & $\stackrel{\varrho}{=}$ & $\begin{array}{l}\infty \\
\infty \\
\pm \\
\pm\end{array}$ & $\begin{array}{l}\hat{\sigma} \\
\hat{z}\end{array}$ & 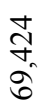 & $\begin{array}{l}\text { के } \\
\hat{\sigma}\end{array}$ & 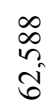 \\
\hline$\ldots$ & & & & & & & & & \\
\hline 61 & $\stackrel{\dot{J}_{n}}{\stackrel{\overbrace{}}{ \pm}}$ & $\begin{array}{l}\stackrel{2}{ \pm} \\
\stackrel{+}{ \pm}\end{array}$ & $\begin{array}{l}0 \\
\stackrel{1}{ } \\
\stackrel{J}{J}\end{array}$ & $\begin{array}{l}n \\
\text { \& } \\
\dot{J}\end{array}$ & \begin{tabular}{l}
0 \\
\multirow{J}{*}{} \\
$=$
\end{tabular} & $\stackrel{n}{\Xi}$ & \begin{tabular}{l}
0 \\
\multirow{f}{0}{} \\
$=$
\end{tabular} & $\begin{array}{l}0 \\
8 \\
0 \\
=\end{array}$ & $\hat{n}$ \\
\hline 62 & 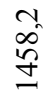 & $\frac{\mathscr{g}}{\nexists}$ & धे & $\begin{array}{l}N \\
\text { N } \\
\end{array}$ & 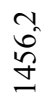 & $\stackrel{0}{\stackrel{0}{ \pm}}$ & $\stackrel{尺}{I}$ & 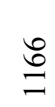 & $\begin{array}{l}2 \\
6 \\
=\end{array}$ \\
\hline 63 & $\begin{array}{l}\nabla_{0} \\
\stackrel{0}{n} \\
\stackrel{n}{2}\end{array}$ & 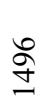 & ڤे & 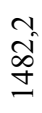 & $\begin{array}{l}\overrightarrow{0} \\
\overrightarrow{0} \\
\dot{0}\end{array}$ & 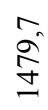 & $\stackrel{\infty}{=}$ & 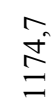 & $\stackrel{\infty}{\stackrel{\infty}{\Xi}}$ \\
\hline 64 & $\begin{array}{l}n \\
n \\
n \\
n \\
n\end{array}$ & $\begin{array}{l}\hat{n} \\
\text { ñ }\end{array}$ & $\hat{\tilde{n}}$ & & $\begin{array}{l}\vec{a} \\
\stackrel{\infty}{ \pm}\end{array}$ & $\begin{array}{l}0 \\
\infty \\
\infty \\
\stackrel{\infty}{+}\end{array}$ & $\begin{array}{l}0 \\
\text { \& } \\
\text { I }\end{array}$ & $\stackrel{\infty}{\Omega}$ & $\begin{array}{l}0 \\
\Omega\end{array}$ \\
\hline$\ldots$ & & & & & & & & & \\
\hline
\end{tabular}
influence of soil (column «-») and under the influence of soils such as G-I and G-VI.

Table 2. Obtained results of natural frequencies of the pipeline 


\begin{tabular}{|c|c|c|c|c|c|c|c|c|c|}
\hline 99 & \begin{tabular}{l}
0 \\
$i$ \\
\multirow{N}{\sim}{}
\end{tabular} & $\frac{\tilde{n}}{\tilde{v}}$ & $\begin{array}{l}\hat{\mathbb{J}} \\
\vec{N}\end{array}$ & $\begin{array}{l}\hat{\infty} \\
\text { ஸे } \\
\text { ঠे }\end{array}$ & 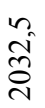 & $\frac{\tilde{m}}{\stackrel{\tilde{\vartheta}}{\sim}}$ & $\begin{array}{l}n \\
\hat{b} \\
\widehat{\delta}\end{array}$ & 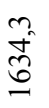 & 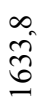 \\
\hline 100 & 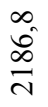 & $\begin{array}{l}\tilde{\infty} \\
\frac{\infty}{N}\end{array}$ & $\frac{\infty}{\sim}$ & $\frac{n}{\tilde{n}}$ & $\vec{a}$ & \begin{tabular}{l}
$n$ \\
$\infty$ \\
\multirow{0}{0}{} \\
\multirow{2}{*}{}
\end{tabular} & $\begin{array}{l}0 \\
\vec{g}\end{array}$ & ڤ్ & స్రి \\
\hline
\end{tabular}

Table 3. Obtained results of natural frequencies of the pipeline

\begin{tabular}{|c|c|c|c|c|c|c|}
\hline \multirow{3}{*}{ Mode } & \multicolumn{6}{|c|}{ Meter pipeline } \\
\hline & \multicolumn{3}{|c|}{$355 \times 8,7$} & \multicolumn{3}{|c|}{$630 \times 15,4$} \\
\hline & - & G -I & $\mathrm{G}-\mathrm{VI}$ & - & G -I & $\overline{G-V I}$ \\
\hline 1 & 2 & 3 & 4 & 5 & 6 & 7 \\
\hline & \multicolumn{6}{|c|}{ Frequency, $\mathrm{Hz}$} \\
\hline 1 & $\begin{array}{l}\infty \\
\stackrel{8}{0} \\
\stackrel{1}{1}\end{array}$ & $\begin{array}{l}\stackrel{2}{\circ} \\
=\end{array}$ & $\begin{array}{l}\infty \\
\approx \\
\cong \\
\varrho\end{array}$ & \begin{tabular}{l}
$\underset{\nabla}{*}$ \\
\multirow{\sigma}{*}{}
\end{tabular} & 0 & 0 \\
\hline 2 & $\begin{array}{l}\stackrel{9}{\exists} \\
\vec{m}\end{array}$ & 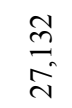 & 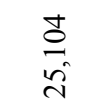 & \begin{tabular}{l}
\multirow{f}{f}{} \\
$\stackrel{f}{J}$
\end{tabular} & 0 & 0 \\
\hline$\ldots$ & & & & & & \\
\hline 61 & \begin{tabular}{l}
\multirow{\infty}{0}{} \\
$\hat{ర}$ \\
$\infty$
\end{tabular} & $\begin{array}{l}0 \\
\text { î } \\
\infty\end{array}$ & $\begin{array}{l}\text { ?ె. } \\
\text { ָే } \\
\infty\end{array}$ & $\begin{array}{l}\hat{\sigma} \\
\hat{n} \\
\hat{q}\end{array}$ & $\hat{\kappa}$ & $\underset{\sigma}{\sigma}$ \\
\hline 62 & $\begin{array}{l}\underset{+}{ } \\
\infty \\
\infty \\
\infty\end{array}$ & $\begin{array}{l}\infty \\
\infty \\
\mathbb{b}\end{array}$ & $\begin{array}{l}\stackrel{d}{d} \\
\underset{d}{\infty}\end{array}$ & $\frac{n}{a}$ & $\frac{\mathfrak{g}}{\stackrel{\sigma}{\circ}}$ & $\begin{array}{l}\stackrel{g}{q} \\
\stackrel{q}{q}\end{array}$ \\
\hline 63 & $\begin{array}{l}\mathbb{J} \\
\infty \\
\infty \\
\infty\end{array}$ & $\begin{array}{l}\infty \\
\infty \\
\infty \\
\infty\end{array}$ & $\begin{array}{l}\vec{m} \\
\tilde{\infty}_{\infty}\end{array}$ & $\frac{\approx}{\approx}$ & $\begin{array}{l}\text { ô } \\
\text { ¿̊ } \\
\text { in }\end{array}$ & $\begin{array}{l}\text { m. } \\
\text { लि } \\
\stackrel{8}{n}\end{array}$ \\
\hline 64 & $\begin{array}{l}2 \\
2 \\
2 \\
\infty\end{array}$ & $\begin{array}{l}\text { to } \\
\text { న̊ } \\
\infty\end{array}$ & $\frac{a}{\infty}$ & $\frac{\sqrt{n}}{n}$ & $\begin{array}{l}8 \\
\stackrel{0}{0} \\
\stackrel{1}{n}\end{array}$ & $\hat{n}$ \\
\hline$\ldots$ & & & & & & \\
\hline 99 & $\stackrel{\hat{\sigma}}{\underline{a}}$ & $\begin{array}{l}\vec{n} \\
= \\
=\end{array}$ & $\begin{array}{l}\vec{t} \\
\exists\end{array}$ & $\begin{array}{l}\hat{\Omega} \\
\hat{\rho}\end{array}$ & $\begin{array}{l}\hat{\imath} \\
\hat{0}\end{array}$ & $\frac{+}{i}$ \\
\hline 100 & $\begin{array}{l}\infty \\
\stackrel{a}{\Xi}\end{array}$ & $\stackrel{\partial}{\stackrel{\partial}{=}}$ & $\begin{array}{l}\stackrel{\circ}{\infty} \\
\infty \\
\stackrel{\infty}{\Xi}\end{array}$ & $\begin{array}{l}\hat{f} \\
\infty \\
\infty \\
\delta\end{array}$ & 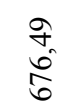 & 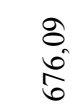 \\
\hline
\end{tabular}

The analysis of the obtained results showed that the frequencies of natural vibrations of free pipelines (without the influence of the soil) and buried (with the influence of the soil) change in the direction of decreasing the value, while the denser soil has a greater effect.

For clarity, graphs of a decrease in the frequency of natural vibrations of various pipelines in the frequency range from 1150 to $1600 \mathrm{~Hz}$ (modes 61-64) are shown, shown in Figures 2 a-c.

Thus, the experimental data obtained in [13-15] were confirmed.
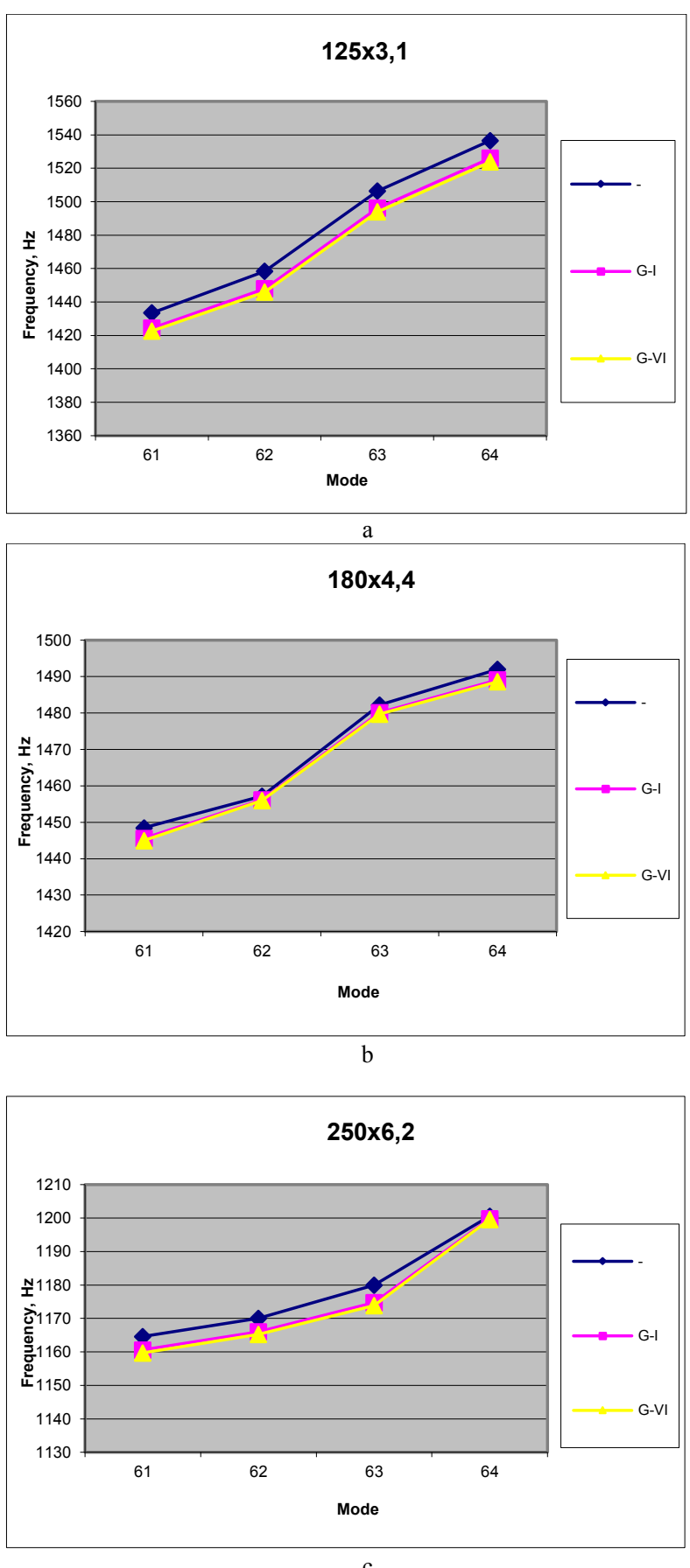

Fig. $2(\mathbf{a}, \mathbf{b}, \mathbf{c})$. Graphs of changes in natural frequencies of vibrations of pipelines of various sizes

\section{Conclusion}

In this work, a modal analysis of natural vibrations of polyethylene pipelines was carried out, both without taking into account the soil pressure, and taking into account the vertical and lateral pressures of various soils. The calculations were performed using the ANSYS software package.

As a result of analytical studies of the influence of various soils on the change in the natural frequency of pipelines of 5 types, it was determined that the soil affects the change in the frequencies of natural vibrations, while the lowest frequency value is achieved when the communication is laid in the soil of 
the G-VI type (heavy clay), which due to its viscosity and plasticity.

The results obtained confirm previous experimental studies. Thus, the well-known dependence of the degree of influence of different soils on the natural frequencies of pipelines significantly increases the reliability of vibration diagnostics of buried communications, facilitates the work on its organization and allows one to build long-term forecasts of operation.

\section{References}

1. F.M. Mustafanov. Field Piping and Equipment, 662 (2004).

2. G.G. Vasiliev, G.E. Korobkov, A.A. Korshak and others. Oil pipeline transport. Textbook. for universities, 2002.

3. Labor safety in industry No. 3, 94, (2019).

4. Udima, P.G. Corrosion Resistant Piping of NonMetallic Materials, 212 (2015).

5. Polyethylene pressure pipes. Specifications: interstate standard GOST 18599-2001: instead of GOST 18599-83: introduced 2003-01-01 / Interstate Council for Standardization, Metrology and Certification, 34 (2008).

6. Adelsky, E.Kh. Hydraulic calculation of pipelines for various purposes, 476 (2013).

7. Vikulin P.D. Hydraulics and Aerodynamics of Water Supply and Wastewater Systems, 386 (2018).

8. Ansys / CFX Program Manual, version 13.0 (2010).

9.V.A. Bruyaka, V. Fokin, E.A. Soldusova, N.A. Glazunova, I. Adeyanov. Engineering Analysis in ANSYS Workbench [Engineering Analysis in ANSYS Workbench], 271 (2010).

10. V.V. Mushroom. Diagnostic models of changes in the technical state of mechanical systems. Moscow Automobile and Road Institute (2007).

11. S.O. Gaponenko, A.E. Kondratyev. Promising methods and techniques for finding hidden channels, cavities and pipelines by the vibroacoustic method, Bulletin of the North Caucasus Federal University No. 2 (47), 9-13 (2015).

12. S.O. Gaponenko, A.E. Kondratyev. Model installation for the development of a method for determining the location of hidden pipelines // News of higher educational institutions. Energy Problems No. 7-8, 123-129 (2014).

13. S.O. Gaponenko. Acoustic-resonance information-measuring complex and methodology for monitoring the location of buried pipelines: abstract of dis. candidate of technical sciences, 22 (2017).

14. S.O. Gaponenko, A.A. Ibadov, A.E. Kondratyev, A.F. Nigmatulin. Mathematical modeling of vibrations of an elastic shell under external influence on the example of a pipeline // Materials of the IX International Youth Scientific and Technical Conference "Electric Power Industry through the Eyes of Youth, 265-268 (2018).

15. S.O. Gaponenko, A.A. Ibadov, A.E. Kondratyev. Determination of informative frequency ranges for monitoring the location of buried pipelines // Scientific progress - creativity of young people №2, 68-71 (2018). 